\title{
羊草的地上-地下功能性状对氮磷施肥梯度的响应 及关联
}

詹书侠 ${ }^{1,2}$ 郑淑霞 ${ }^{1}$ 王扬 ${ }^{1,2}$ 白永飞 ${ }^{1 *}$

${ }^{1}$ 中国科学院植物研究所植被与环境变化国家重点实验室, 北京 100093 ; $^{2}$ 中国科学院大学, 北京 100049

摘 要 羊草(Leymus chinensis)是我国北方典型草原群落的主要建群种和优势种, 由于长期的过度放牧, 羊草草原生态系统 的结构和功能严重退化。养分添加作为恢复草地生态系统的一种管理措施, 其应用目前还处于实验性研究阶段。关于羊草的 地上-地下功能性状对养分添加, 尤其是 $P$ 添加的响应研究较少, 相关机制尚不十分清楚。为此, 该文以羊草为研究对象, 通过 温室栽培进行 $\mathrm{N}\left(50,100,250 \mathrm{mg} \mathrm{N} \cdot \mathrm{kg}^{-1}\right)$ 和P $\left(5,10,25 \mathrm{mg} \mathrm{P} \cdot \mathrm{kg}^{-1}\right)$ 各3个水平的养分添加实验, 研究羊草的地上-地下功能性状 对 N、P添加的响应及适应机制。主要研究结果表明: 1)羊草的地上生物量和总生物量主要受 $\mathrm{N}$ 添加的影响, N添加显著提高了 羊草的地上生物量, 而地下生物量主要受 $\mathrm{P}$ 添加的影响, 尤其在中 $\mathrm{N}$ 和高 $\mathrm{N}$ 水平, $\mathrm{P}$ 添加显著降低了羊草的地下生物量。羊草的 根冠比受 $N 、 P$ 添加的共同影响, 随着 $\mathrm{N} 、 \mathrm{P}$ 添加梯度加大, 根冠比显著降低, $\mathrm{N} 、 \mathrm{P}$ 添加促进了羊草生物量向地上部分的分配和 $\mathrm{N} 、 \mathrm{P}$ 向叶片的分配。2)在低 $\mathrm{N}$ 和高 $\mathrm{N}$ 水平, 羊草对 $\mathrm{P}$ 添加的响应与适应机制不同。低 $\mathrm{N}$ 水平, 羊草主要通过增加光合速率和比 根长 $(S R L)$, 提高光合能力和根系对 $\mathrm{N}$ 的获取能力促进地上部分的生长, 而根系对 $\mathrm{P}$ 的吸收有利于地下部分的生长; 在高 $\mathrm{N}$ 水 平, $\mathrm{P}$ 添加对羊草的个体生长无明显促进作用, 甚至地下生物量明显受到 $\mathrm{P}$ 素抑制, 羊草主要通过保持较高的比叶面积(SLA)和 $S R L$, 提高对光资源的截获能力和根系对 $\mathrm{N}$ 的获取和吸收能力, 维持地上部分的生长。3)相对于地上性状, $\mathrm{P}$ 添加对羊草的地下 性状影响更大, 羊草的 $S L A$ 与 $S R L$ 呈较弱的正相关关系, 表明叶片与根系在资源获取和利用方面具有相对独立性。

关键词 羊草; 植物功能性状; 地上-地下关系; 氮磷分配; 氮磷添加

引用格式: 詹书侠, 郑淑霞, 王扬, 白永飞 (2016). 羊草的地上-地下功能性状对氮磷施肥梯度的响应及关联. 植物生态学报, 40, 36-47. doi: 10.17521/cjpe.2015.0164

\section{Response and correlation of above- and below-ground functional traits of Leymus chinensis to nitrogen and phosphorus additions}

ZHAN Shu-Xia ${ }^{1,2}$, ZHENG Shu-Xia ${ }^{1}$, WANG Yang ${ }^{1,2}$, and BAI Yong-Fei ${ }^{{ }^{*}}$

${ }^{1}$ State Key Laboratory of Vegetation and Environmental Change, Institute of Botany, Chinese Academy of Sciences, Beijing 100093, China; and ${ }^{2}$ University of Chinese Academy of Sciences, Beijing 100049, China

\begin{abstract}
Aims Leymus chinensis is a constructive and dominant species in typical steppe of northern China. The structure and functions of $L$. chinensis grassland ecosystem has been degenerated seriously due to long-term overgrazing in recent decades. As an effective measure to restore the degraded grasslands, the effects of nutrient addition on plant growth and ecosystem structure and functioning have been paid more attention in manipulation experimental research. The effects of nutrient addition, especially $\mathrm{P}$ addition on the above- and below-ground functional traits of L. chinensis have rarely been studied; particularly the underpinning mechanisms remain unclear. Our objective is to examine the responses and adaptive mechanisms of $L$. chinensis to different levels of $\mathrm{N}$ and $\mathrm{P}$ additions.
\end{abstract}

Methods We conducted a culture experiment in the greenhouse, with three levels of N (50, 100 and $250 \mathrm{mg}$ $\mathrm{N} \cdot \mathrm{kg}^{-1}$ ) and $\mathrm{P}\left(5,10\right.$ and $\left.25 \mathrm{mg} \mathrm{P} \cdot \mathrm{kg}^{-1}\right)$ addition treatments. The above- and below-ground biomass, leaf traits (e.g., specific leaf area, leaf $\mathrm{N}$ and $\mathrm{P}$ contents) and root traits (e.g., specific root length, root $\mathrm{N}$ and $\mathrm{P}$ contents) of L. chinensis were determined in this study.

Important findings Our results showed that: 1 ) the aboveground biomass and total biomass of $L$. chinensis were mostly affected by $\mathrm{N}$ addition, while the belowground biomass was mainly affected by $\mathrm{P}$ addition. $\mathrm{N}$ addition greatly enhanced the aboveground biomass of $L$. chinensis, while $\mathrm{P}$ addition reduced the belowground biomass at

收稿日期Received: 2015-05-07 接受日期Accepted: 2015-10-04

* 通信作者Author for correspondence (E-mail: yfbai@ibcas.ac.cn) 
the moderate and high $\mathrm{N}$ levels. The root-shoot ratio of $L$. chinensis was influenced by both $\mathrm{N}$ and $\mathrm{P}$ additions, and root-shoot ratio decreased with increasing $\mathrm{N}$ and $\mathrm{P}$ levels. $\mathrm{N}$ and $\mathrm{P}$ additions promoted more biomass and $\mathrm{N}$ and $\mathrm{P}$ allocations to aboveground and leaf biomass. 2) Leymus chinensis showed different responses and adaptive mechanisms to $\mathrm{P}$ addition at low and high $\mathrm{N}$ levels. At low $\mathrm{N}$ level, L. chinensis exhibited high photosynthetic rate and specific root length (SRL) to improve photosynthetic capacity and root $\mathrm{N}$ acquisition, which promoted aboveground biomass. High root P content was favorable for belowground biomass. At high $\mathrm{N}$ level, $\mathrm{P}$ addition did not significantly affect plant growth of $L$. chinensis, even reduced its belowground biomass. Leymus chinensis showed high specific leaf area (SLA) and $S R L$ to improve light interception and $\mathrm{N}$ acquisition in order to maintain stable aboveground biomass. 3) P addition greatly impacted below-ground than above-ground functional traits. SLA exhibited a weakly positive correlation with $S R L$, indicating $L$. chinensis exhibited relatively independence of resource acquirement and utilization between leaf and root functional traits.

Key words Leymus chinensis, plant functional traits, above- and below-ground relationships, nitrogen and phosphorus allocation, nitrogen and phosphorus additions

Citation: Zhan SX, Zheng SX, Wang Y, Bai YF (2016). Response and correlation of above- and below-ground functional traits of Leymus chinensis to nitrogen and phosphorus additions. Chinese Journal of Plant Ecology, 40, 36-47. doi: 10.17521/cjpe.2015.0164

羊草(Leymus chinensis)是多年生根茎禾草，由 于其营养繁殖能力很强, 且具有典型的克隆生长特 性, 是我国北方典型草原的主要建群种或优势种, 在东北草原和内蒙古草原经常形成大面积的单优种 植被(李永宏, 1993)。自1980年以来, 由于长期的过 度放牧, 我国北方草原生态系统的结构和功能严重 退化, 羊草种群也受到了明显的影响, 其生物量和 密度显著降低(王仁忠, 1997; 王玉辉等, 2002)。养分 添加 (主要是 $\mathrm{N}$ 素添加) 是恢复退化草地生态系统的 一种有效手段, 但目前在草地的恢复与治理上应用 较少(潘庆民等, 2005)。因此, 研究羊草对养分添加 的响应与适应机制, 对于我国草地生态系统的恢复 与管理具有重要意义。

关于羊草的功能性状对 $\mathrm{N}$ 素添加的响应及其适 应策略, 已经开展了较多的研究, 但在不同组织水 平下, 研究结果也不尽相同。例如, 在生态计量化学 方面, 通过在内蒙古典型草原进行的养分添加实验 研究发现: N添加提高了羊草的叶片 $\mathrm{N}$ 含量, 但对叶 片P含量没有显著影响(白雪等, 2014)。N添加也能显 著提高羊草绿叶和衰老叶片的 $\mathrm{N} 、 \mathrm{P}$ 含量, 从而降低 叶片对 $\mathrm{N}$ 和 $\mathrm{P}$ 的再吸收, 整体上提高 $\mathrm{N}$ 和 $\mathrm{P}$ 在植物体 内的周转速率(Lü et al., 2013)。根据生长速率假说 (growth rate hypothesis), 羊草的生长速率与全 $\mathrm{P}$ 含 量存在正相关关系, 而与 $\mathrm{N}: \mathrm{P}$ 存在负相关关系, 不 同来源的羊草种植在同一环境条件下, 来自 $\mathrm{N} 、 \mathrm{P}$ 含 量较高土壤的羊草具有较高的生长速率, 这可能是 羊草对特定地域生境条件长期适应的结果(徐劲草 和许新宜, 2013)。也有研究发现, 羊草植株的N:P随
着 $\mathrm{N}$ 添加在一定范围内保持稳定 (Zhang et al., 2004)。从生理特性方面, Chen等(2005)研究发现, N 添加能够提高羊草的最大光合速率, 但对羊草的净 光合速率、蒸腾速率和气孔导度没有显著影响; 随 着 $\mathrm{N}$ 添加梯度加大, 羊草的水分利用效率增加, 而 $\mathrm{N}$ 素利用效率降低。万宏伟等(2008)研究发现羊草通 过增加比叶面积 $(S L A)$ 和叶片 $\mathrm{N}$ 含量提高对光的竞 争能力。白雪等(2014)研究发现, 羊草对 N添加的响 应因组织水平而异, 也受年际间降水变化的影响, 羊草通过增加SLA、叶片大小和叶片 $\mathrm{N}$ 含量, 提高整 体光合能力, 从而促进个体生长。这些结果主要是 定性描述羊草对 $\mathrm{N}$ 变化的生理生态响应, 并没有在 机理上对这些响应做出解释。

和 $\mathrm{N}$ 一样, $\mathrm{P}$ 也是植物生长的主要养分限制因 子, 因此 $\mathrm{N}$ 素和 $\mathrm{P}$ 素添加均被用于恢复退化的草地 生态系统, 以恢复生态系统的生产力。目前, 关于羊 草功能性状对养分添加响应的研究多集中在 $\mathrm{N}$ 素添 加(Chen et al., 2005; 万宏伟等, 2008; Bai et al., 2010; Lan \& Bai, 2012; Lü et al., 2013), 而关于P添 加以及 $\mathrm{N}$ 和 $\mathrm{P}$ 交互作用对羊草功能性状的影响研究 得较少(黄菊荣等, 2012; 白雪等, 2014), 相关机制 尚不十分清楚。白雪等(2014)发现, 尽管羊草草原主 要受 $\mathrm{N}$ 素限制, 但在一定条件下也受 $\mathrm{P}$ 素限制。因此, 关于 $\mathrm{P}$ 添加对羊草植物功能性状的影响近年来逐渐 受到关注。例如, 白雪等(2014)研究发现, P添加提高 了羊草的叶片N和P含量; 黄菊荣等(2012)的研究表 明随着 $\mathrm{P}$ 添加梯度增加, 羊草的根冠比降低。而 且, $\mathrm{N}$ 供应水平的变化也影响了羊草对 $\mathrm{P}$ 的吸收 
(Marklein \& Houlton, 2012), 因此, N、P供应比例的 改变可能会对植物功能性状产生较大的影响。通过 控制实验, 开展不同 $\mathrm{N}$ 添加水平下植物对 $\mathrm{P}$ 添加梯 度的响应与适应机制的研究, 有助于更好地理解植 物对养分环境波动的适应能力。

目前, 已有的养分添加实验研究主要针对羊草 地上部分的功能性状, 很少涉及羊草地下部分 (如 根系)的功能性状, 尤其是关于羊草的地上-地下功 能性状及其关联的研究较少。Liu等(2010)的研究表 明在群落、局地、区域和样带尺度上, 包括羊草在 内的许多草原植物的地上和地下功能性状之间具有 一定的联系, 如叶片 $\mathrm{N}$ 与根系 $\mathrm{N}$ 含量、SLA 与比根长 $(S R L)$ 之间均呈显著的正相关关系。而且, 黄菊荣等 (2012)研究发现, 随着 N和P添加量的增加, 羊草的 地上、地下生物量和养分库呈现先增加后降低的趋 势, 根冠比呈降低的趋势。因此, 养分添加可能会改 变羊草的地上-地下功能性状及其关联, 但缺乏相 关的研究来进行验证。开展关于羊草的地上-地下功 能性状对 N、P添加的响应及关联研究, 有助于全面 理解和揭示羊草对养分添加的响应与适应机制, 为 退化草地生态系统的恢复提供理论依据。

由于野外实验不可避免地要受到外界环境(如 气候、土壤异质性等)和生物因素(如物种间的相互作 用)的影响, 而室内栽培实验能够较好地避免这些因 素的影响, 有利于揭示羊草对养分添加的响应与适 应机制。为此, 我们设计了室内羊草栽培实验, 采用 了低、中、高 3 个 $\mathrm{N}$ 和P添加梯度的交互处理, 以全面 研究N、P及其交互作用对羊草整株性状、叶片和根 系功能性状的影响, 本研究拟回答两个方面的科学 问题: 1) N、P添加对羊草个体的地上与地下生物量及 养分分配如何影响? 对叶片(如SLA、叶片 $\mathrm{N}$ 和 $\mathrm{P}$ 含量) 与根系(如 $S R L$ 、根系 $\mathrm{N}$ 和 $\mathrm{P}$ 含量)性状如何影响? 2)羊 草的地上与地下功能性状之间有何关联? 是否存在 权衡(trade-offs)或协同(synergies)关系? 在低 $\mathrm{N}$ 和高 $\mathrm{N}$ 水平, 羊草对 $\mathrm{P}$ 添加的响应及适应机制是什么?

\section{1 材料和方法}

\section{1 试验设计}

本实验在中国科学院植物研究所的温室内进 行。2010年4月初, 以蛭石作为培养基质, 在约 $25{ }^{\circ} \mathrm{C}$ 的温室内选取羊草种子进行幼苗萌发试验。待羊草 幼苗长至约 $5 \mathrm{~cm}$ 高时, 选取大小较一致的植株6-8
株移栽至塑料盆(直径 $15 \mathrm{~cm}$ 、高15 cm)中, 共准备 100 盆移栽好的羊草幼苗备用。

实验设计包括 2 个养分 $(\mathrm{N} 、 \mathrm{P})$ 添加处理, 每个养 分设置3个水平, 其中 $\mathrm{N}$ 添加的 3 个浓度水平为: $\mathrm{N} 1$ $=50 \mathrm{mg} \cdot \mathrm{kg}^{-1} 、 \mathrm{~N} 2=100 \mathrm{mg} \cdot \mathrm{kg}^{-1} 、 \mathrm{~N} 3=250 \mathrm{mg} \cdot \mathrm{kg}^{-1}, \mathrm{P}$ 添加的 3 个浓度水平为: $\mathrm{P} 1=5 \mathrm{mg} \cdot \mathrm{kg}^{-1} 、 \mathrm{P} 2=10$ $\mathrm{mg} \cdot \mathrm{kg}^{-1} 、 \mathrm{P3}=25 \mathrm{mg} \cdot \mathrm{kg}^{-1}$, 添加量均为纯 $\mathrm{N}$ 或纯 $\mathrm{P}$ 的 质量与花盆内蛭石质量之比。本实验共设计 10 个处 理, 每个处理均包含不同的 $\mathrm{N}$ 和 $\mathrm{P}$ 添加梯度, 具体 为: N0P0 (对照)、N1P1、N1P2、N1P3、N2P1、N2P2、 N2P3、N3P1、N3P2、N3P3, 每个处理10个重复。 $\mathrm{N}$ 和P添加的浓度水平是参考中国科学院内蒙古草 原生态系统定位研究站自2000年设置的长期 $\mathrm{N}$ 素 (0、1.75、5.25、10.5、17.5、28.0 g N $\left.\cdot \mathrm{m}^{-2}\right)$ 和 $\mathrm{P}$ 素( 0 、 2、4、8、16、32 $\mathrm{g} \mathrm{P}_{2} \mathrm{O}_{5} \cdot \mathrm{m}^{-2}$ )添加实验平台(Bai et al., 2010)的实验处理设置的。由于野外实验是按施肥面 积换算的，与室内实验按盆栽土壤质量换算不同， 故而根据野外实验的养分处理水平, 本实验将 $\mathrm{N}$ 添 加量设计为 $50 、 100 、 250 \mathrm{mg} \mathrm{N} \cdot \mathrm{kg}^{-1}$, 而 $\mathrm{P}$ 添加量与 $\mathrm{N}$ 的比例按1:10计算, 设计为 $5 、 10 、 25 \mathrm{mg} \mathrm{P} \cdot \mathrm{kg}^{-1}$ 。N 、 $\mathrm{P}$ 养分的添加采用配制并稀释好的 $\mathrm{NH}_{4} \mathrm{NO}_{3}$ 和 $\mathrm{Na}_{2} \mathrm{HPO}_{4}$ 溶液, 同时在对照和所有处理中均添加了 由 $\mathrm{ZnSO}_{4} 、 \mathrm{MnCl}_{2} 、 \mathrm{Na}_{2} \mathrm{MoO}_{4} 、 \mathrm{H}_{3} \mathrm{BO}_{3}$ 配置的微量元 素混合溶液, 以保证植物不受其他元素的限制。2010 年5月初, 待羊草幼苗完全成活后, 根据N、P添加处 理, 分6次每隔 10 天加入 $\mathrm{Na}_{2} \mathrm{HPO}_{4}$ 和 $\mathrm{NH}_{4} \mathrm{NO}_{3}$ 营养液。

\section{2 植物功能性状测定}

2010年7月初, N、P添加处理约60天后, 羊草叶 片生长至成熟状态, 进行植物功能性状的观测。首 先进行叶片光合生理性状的测定。利用LI-6400便携 式光合作用测定系统 (LI-COR, Lincoln, USA), 在 光强 $1500 \mu \mathrm{mol}$ photons $\cdot \mathrm{m}^{-2} \cdot \mathrm{s}^{-1} 、 \mathrm{CO}_{2}$ 浓度 400 $\mu \mathrm{mol} \cdot \mathrm{mol}^{-1}$ 、叶片温度 $20{ }^{\circ} \mathrm{C}$ 及空气流通速率 500 $\mu \mathrm{mol} \cdot \mathrm{s}^{-1}$ 的控制条件下, 测定羊草叶片的净光合速 率 $\left(P_{\mathrm{n}}\right)$ 、蒸腾速率 $\left(T_{\mathrm{r}}\right) 、$ 气孔导度 $\left(G_{\mathrm{s}}\right)$ 等气体交换参 数, 进一步计算水分利用效率 $\left(W U E=P_{\mathrm{n}} / T_{\mathrm{r}}\right)$ 。选取 羊草最顶端完全展开的健康叶片, 每盆羊草测定 1-2个叶片, 每个处理测定10盆重复。

羊草的光合生理性状测定完成后, 进行整株性 状、叶片和根系性状的观测。对盆栽羊草进行破坏 性取样, 将植株全部挖出后清洗干净, 将植株分为 根、茎、叶 3 个部分, 分别称量其鲜质量。利用 
LI-3100 C型便携式叶面积仪 (LI-COR, Lincoln, USA)测定叶片面积, 利用Winrhizo根系分析系统 (Regent, Quebec, Canada)扫描测定根系的总长度, 然后将各部分样品于 $70{ }^{\circ} \mathrm{C}$ 烘干, 用 $1 / 10000$ 天平称 量。羊草个体的地上生物量为茎和叶的质量之和, 地下生物量为根系总质量, 总生物量为地上与地下 生物量之和, 根冠比为地上与地下生物量之比。SLA 为叶片面积与叶片质量之比, $S R L$ 为根系总长度与 根系质量之比。进一步对叶片和根系样品进行 $\mathrm{N} 、 \mathrm{P}$ 养分分析, 全N用CHNOS元素分析仪(vario EL III, Elementar Analysensysteme GmbH, Hanau, Germany) 测定, 全P用钼锑锌比色法(6505紫外分光光度计, Jenway, Stone, UK)测定。羊草的叶片 N、P总量分别 为叶片生物量与 $\mathrm{N} 、 \mathrm{P}$ 含量的乘积, 根系 $\mathrm{N} 、 \mathrm{P}$ 总量分 别为根系生物量与 $\mathrm{N} 、 \mathrm{P}$ 含量的乘积, 羊草的 $\mathrm{N}$ 分配 为叶片总 $\mathrm{N}$ 含量与根系总 $\mathrm{N}$ 含量之比, $\mathrm{P}$ 分配为叶片 总 $\mathrm{P}$ 含量与根系总 $\mathrm{P}$ 含量之比。

\section{3 统计分析}

数据分析利用SAS 9.2 (SAS, Cary, USA) 统计 分析软件。采用双因素方差分析, 将不同水平的 $\mathrm{N}$ $(\mathrm{N} 1 、 \mathrm{~N} 2 、 \mathrm{~N} 3) 、 \mathrm{P}(\mathrm{P} 1 、 \mathrm{P} 2 、 \mathrm{P} 3)$ 添加处理作为固定 因子, 分析不同 $\mathrm{N} 、 \mathrm{P}$ 添加水平及交互作用对羊草功 能性状的影响。同一 $\mathrm{N}$ 水平下, 不同P添加处理之间 的差异采用单因素方差分析和最小显著差异 $(L S D)$ 多重比较方法。用一般线性回归分析法分析所有处 理下羊草的地上性状与地下性状之间的关系, 并分 别对低 $\mathrm{N}$ 和高 $\mathrm{N}$ 水平所有 $\mathrm{P}$ 添加处理下, 羊草的整株 性状与叶片、根系性状之间的关系进行相关分析。

\section{2 结果和分析}

\section{1 羊草地上、地下生物量、总生物量和根冠比对 N、P添加的响应}

不同 $\mathrm{N} 、 \mathrm{P}$ 添加处理的双因素方差分析结果表 明: N添加对羊草个体的地上生物量、地下生物量、 总生物量和根冠比影响显著; P添加及 $N$, P交互处理 对羊草个体的地下生物量和根冠比影响显著(表1)。 在低 $\mathrm{N}$ 水平, 羊草的地上生物量随着 $\mathrm{P}$ 添加梯度而 升高, 在中、高 $\mathrm{N}$ 水平, 羊草的地上生物量在不同 $\mathrm{P}$ 处理中差异不显著(图1)。与地上生物量相反, 羊草 的地下生物量在低 $\mathrm{N}$ 水平对 $\mathrm{P}$ 添加的响应不显著, 而在中、高 $\mathrm{N}$ 水平, 地下生物量随着 $\mathrm{P}$ 添加梯度而降 低。羊草的总生物量随着 $\mathrm{N}$ 添加梯度而显著上升 $(p<$
0.0001 ), 但在相同水平的 $\mathrm{N}$ 添加处理中, 总生物量 对不同P添加的响应没有显著差异。羊草根冠比随 着 $\mathrm{N}$ 和P添加的梯度, 均显著降低 $(p<0.0001)$, 在 低、中、高 3 个 $\mathrm{N}$ 水平下, 羊草根冠比对 $\mathrm{P}$ 添加的响 应均表现出P1 $>$ P2 $>$ P3的趋势。

\section{2 叶片和根系生物量间的 $N 、 P$ 分配}

$\mathrm{N}$ 和P添加对羊草 $\mathrm{N} 、 \mathrm{P}$ 在叶片与根系生物量之 间的分配(以总 $\mathrm{N} 、 \mathrm{P}$ 质量比表示)均有显著影响(表 1)。在低 $N$ 和中 $N$ 水平, $P$ 添加显著提高了 $N$ 向叶片生 物量的分配比例; 而在高 $\mathrm{N}$ 水平, $\mathrm{P}$ 添加对 $\mathrm{N}$ 分配的 影响不显著, 但 $\mathrm{N}$ 向叶片生物量的分配比例显著高 于低 $\mathrm{N}$ 和中 $\mathrm{N}$ 水平(图2)。在低、中、高 3 个 $\mathrm{N}$ 水平下, $\mathrm{P}$ 添加均显著提高了 $\mathrm{P}$ 向叶片生物量的分配比例, 且 在高 $\mathrm{N}$ 水平的分配比例明显高于低 $\mathrm{N}$ 和中 $\mathrm{N}$ 水平。总 的来看, 在高 $\mathrm{N}$ 水平, $\mathrm{N}$ 向叶片生物量的分配比例比 低 $\mathrm{N}$ 水平提高了 4.2 倍, 而 $\mathrm{P}$ 向叶片生物量的分配比 例提高了2.8倍。

\section{3 叶片和根系 N、P含量和 N:P 比对 $N 、 P$ 添加的 响应}

$\mathrm{N}$ 添加对羊草的叶片和根系 $\mathrm{N}$ 含量、叶片和根系 $\mathrm{P}$ 含量, 以及叶片和根系 $\mathrm{N}: \mathrm{P}$ 比均有显著影响, 而 $\mathrm{P}$ 添加及 $\mathrm{N} 、 \mathrm{P}$ 交互处理对根系 $\mathrm{N}$ 含量、叶片和根系 $\mathrm{P}$ 含量, 以及叶片和根系 $\mathrm{N}$ : $\mathrm{P}$ 比影响显著(表1)。叶片 $\mathrm{N}$ 含量随着 $\mathrm{N}$ 添加而显著升高 $(p<0.0001)$, 在低、中、 高3个 $\mathrm{N}$ 水平下, 叶片 $\mathrm{N}$ 含量的平均值分别为 $2.02 \%$ 、 $2.57 \%$ 和 $4.27 \%$, 但叶片 $\mathrm{N}$ 含量对 $\mathrm{P}$ 添加响应不显著 (图2)。根系 $\mathrm{N}$ 含量也随着 $\mathrm{N}$ 添加而显著升高 $(p<$ $0.0001), 3$ 个 $\mathrm{N}$ 水平中, 根系 $\mathrm{N}$ 含量的平均值分别为 $0.97 \% 、 1.09 \%$ 和 $1.98 \%$, 且在高 $\mathrm{N}$ 水平下根系 $\mathrm{N}$ 含量 随着 $\mathrm{P}$ 添加而增加。叶片和根系 $\mathrm{P}$ 含量对 $\mathrm{N}$ 和 $\mathrm{P}$ 添加的 总体响应均显著, 在低 $\mathrm{N}$ 和高 $\mathrm{N}$ 水平, 叶片 $\mathrm{P}$ 含量随 着 $\mathrm{P}$ 添加而增加, 而在低 $\mathrm{N}$ 和中 $\mathrm{N}$ 水平, 根系 $\mathrm{P}$ 含量 随着 $\mathrm{P}$ 添加而降低。总体来看, 羊草叶片的 $\mathrm{N}$ 含量显 著高于根系 $\mathrm{N}$ 含量, 而叶片 $\mathrm{P}$ 和根系 $\mathrm{P}$ 含量大致相 当。叶片和根系对 $\mathrm{N}$ 添加的响应趋势较为一致, 而对 $\mathrm{P}$ 添加的响应有所不同。羊草叶片的N:P (10-15)远 高于根系的 N:P (4.5-9.0)。在低 $\mathrm{N}$ 和高 $\mathrm{N}$ 水平, 叶片 $\mathrm{N}$ : $\mathrm{P}$ 随着 $\mathrm{P}$ 添加而降低, 而在低 $\mathrm{N}$ 和中 $\mathrm{N}$ 水平, 根系 $\mathrm{N}: \mathrm{P}$ 随着P添加而增加(图3)。

\section{$2.4 S L A$ 和SRL对N、P添加的响应}

$\mathrm{N}$ 和 $\mathrm{P}$ 添加对羊草的 $S L A$ 和 $S R L$ 均有显著影响, $\mathrm{N} 、 \mathrm{P}$ 交互处理仅对羊草的 $S R L$ 影响显著(表1)。SLA 

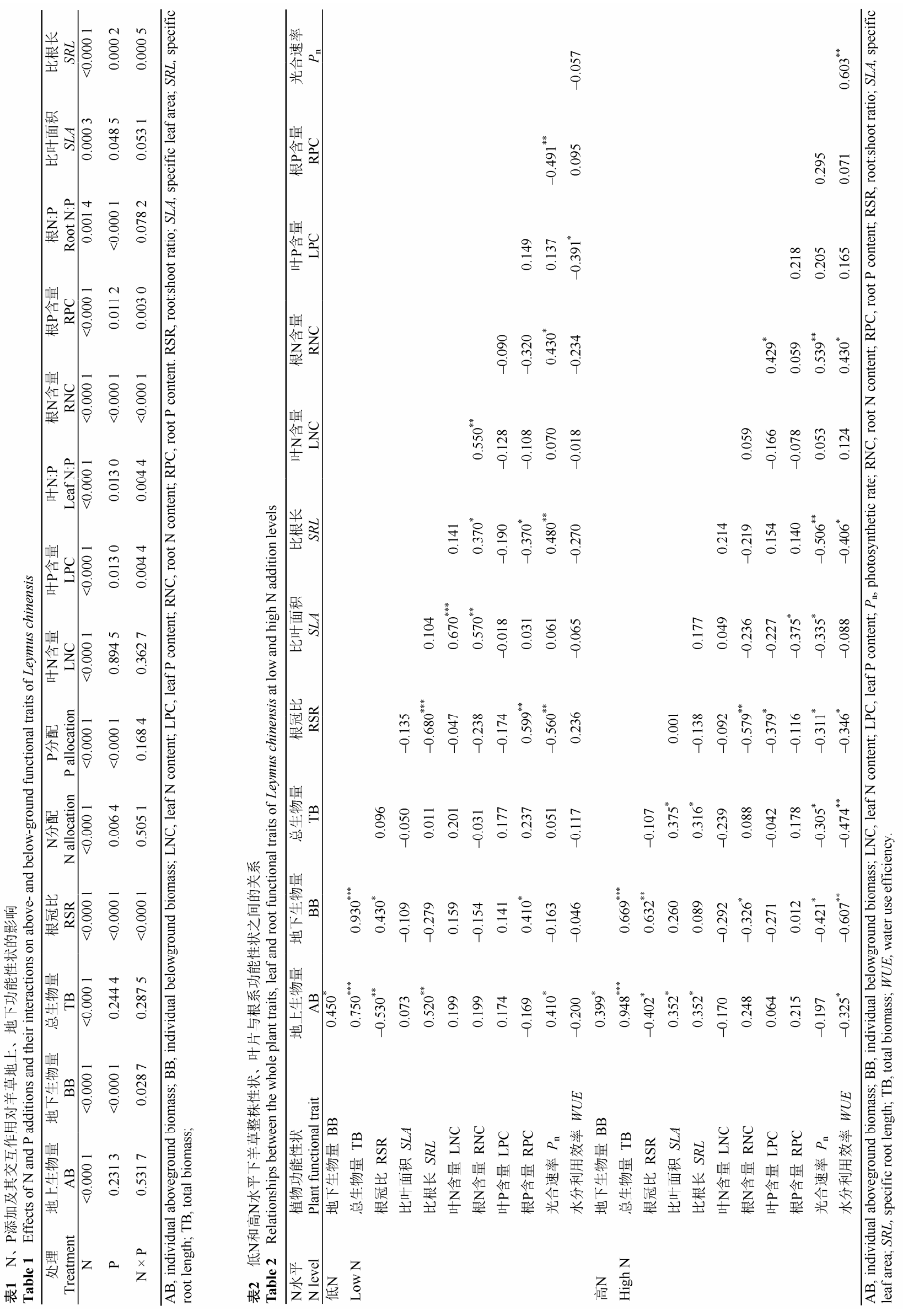

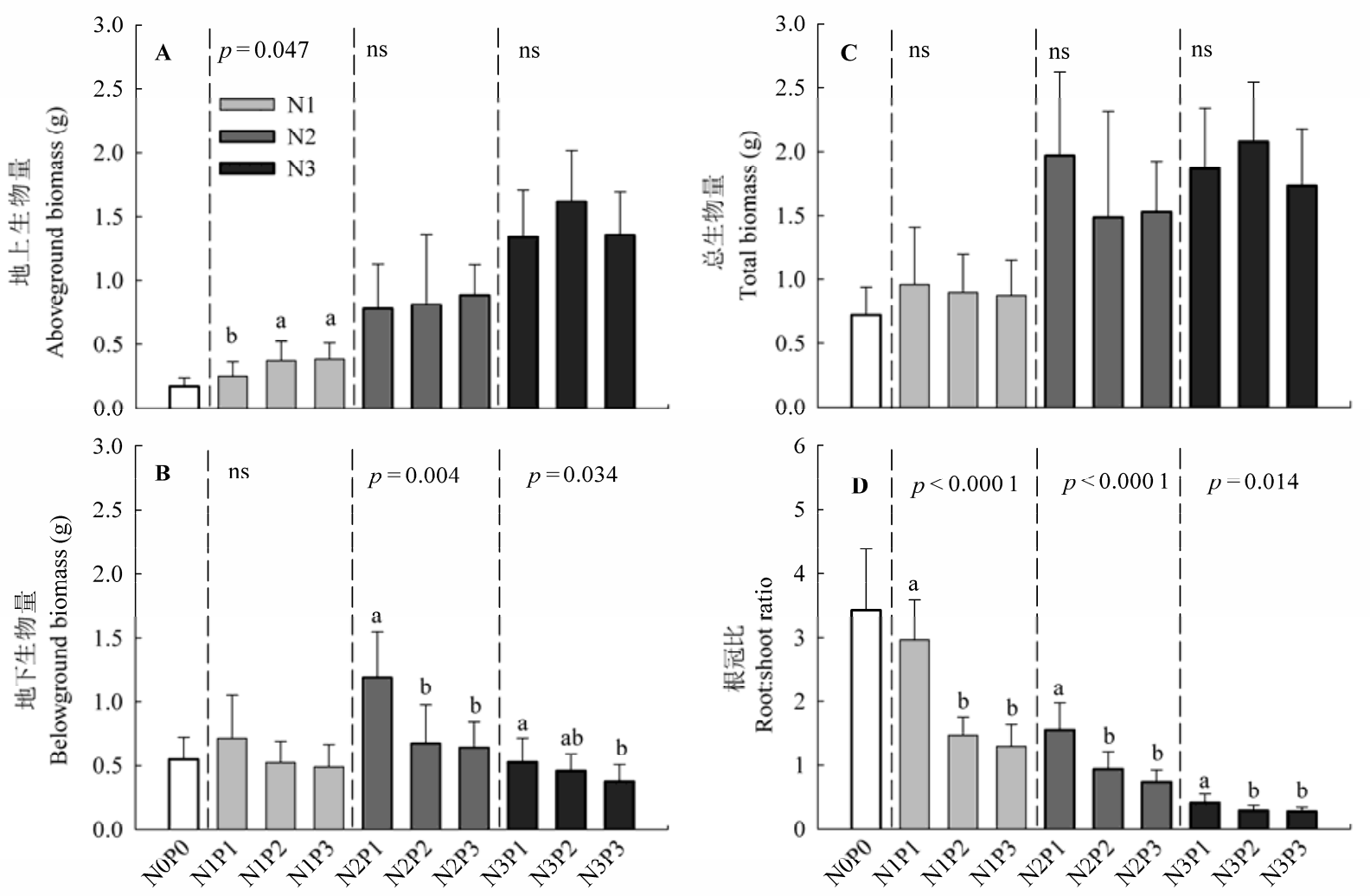

处埋 Treatment

处 理 Treâtiment

图1 氮、磷添加对羊草个体的地上生物量 $(\mathbf{A}) 、$ 地下生物量 $(\mathbf{B}) 、$ 总生物量 $(\mathbf{C})$ 和根冠比(D)的影响(平均值土标准误差)。不同字 母代表在相同 $\mathrm{N}$ 添加水平下, 不同 $\mathrm{P}$ 添加处理之间差异显著 $(p<0.05), p$ 值为显著性水平, ns 表示 $\mathrm{P}$ 处理间差异不显著。 N0P0, 对 照; N1、N2、N3分别表示低、中、高N水平; P1、P2、P3分别表示低、中、高P水平。

Fig. 1 Effects of $\mathrm{N}$ and $\mathrm{P}$ additions on individual aboveground biomass (A), belowground biomass (B), total biomass (C), and root: shoot ratio $(\mathbf{D})$ of Leymus chinensis (mean $\pm S E$ ). Different letters indicate significant difference $(p<0.05)$ among different $\mathrm{P}$ treatments at the same $\mathrm{N}$ level. $p$ values indicate significant levels, and ns indicates non-significant difference among $\mathrm{P}$ treatments. N0P0, control; N1, N2, N3 represent low, moderate and high N levels, and P1, P2, P3 represent low, moderate and high P levels.
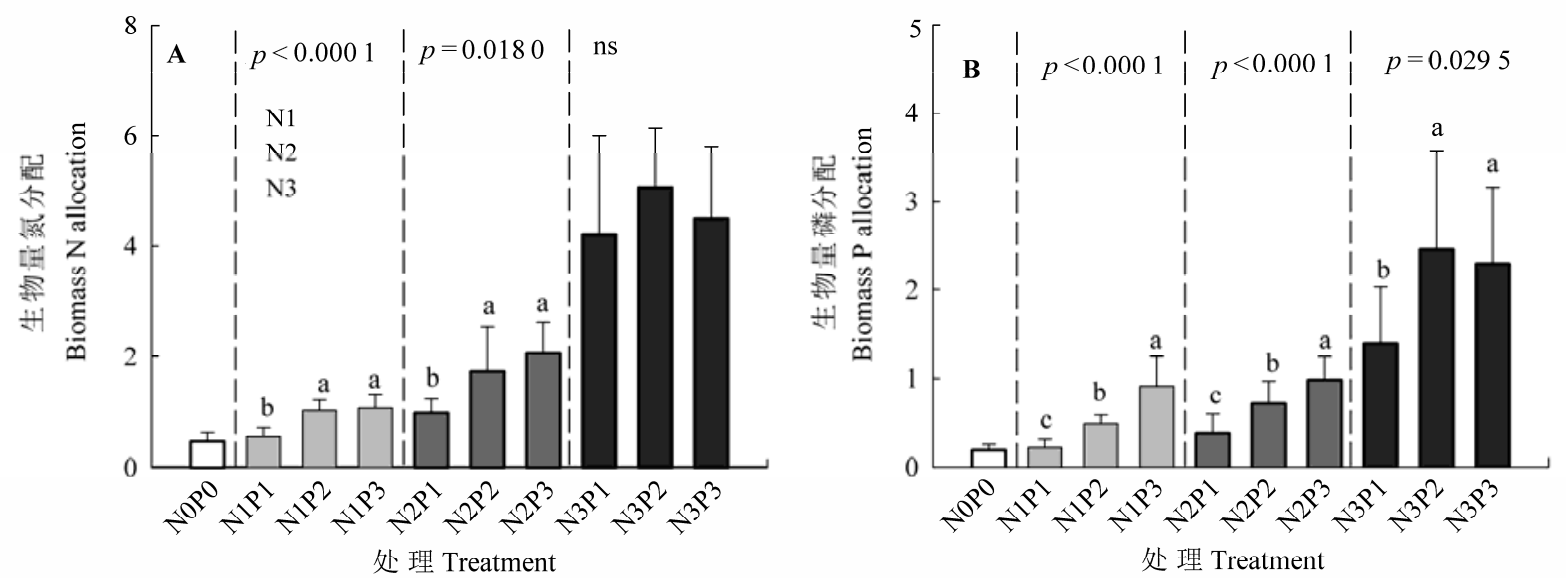

图2 氮、磷添加对羊草叶片与根系生物量 $\mathrm{N} 、 \mathrm{P}$ 分配 (A, B)的影响(平均值土标准误差)。生物量 $\mathrm{N} 、 \mathrm{P}$ 分配分别为叶片与根系总 $\mathrm{N} 、 \mathrm{P}$ 质量之比。不同字母代表在相同 $\mathrm{N}$ 添加水平下, 不同 $\mathrm{P}$ 添加处理之间差异显著 $(p<0.05), p$ 值为显著性水平, $\mathrm{ns}$ 表示 $\mathrm{P}$ 处理间 差异不显著。N0P0, 对照; N1、N2、N3分别表示低、中、高N水平; P1、P2、P3分别表示低、中、高P水平。

Fig. 2 Effects of $\mathrm{N}$ and $\mathrm{P}$ additions on $\mathrm{N}(\mathbf{A})$ and $\mathrm{P}(\mathbf{B})$ allocation between leaf and root biomass of Leymus chinensis (mean \pm SE). $\mathrm{N}$ allocation is calculated as the ratio of leaf $\mathrm{N}$ biomass to root $\mathrm{N}$ biomass, and $\mathrm{P}$ allocation is the ratio of leaf $\mathrm{P}$ biomass to root $\mathrm{P}$ biomass. Different letters indicate significant difference $(p<0.05)$ among different $\mathrm{P}$ treatments at the same $\mathrm{N}$ level. $p$ values indicate significant levels, and ns indicates non-significant difference among P treatments. N0P0, control; N1, N2, N3 represent low, moderate and high N levels, and P1, P2, P3 represent low, moderate and high P levels. 

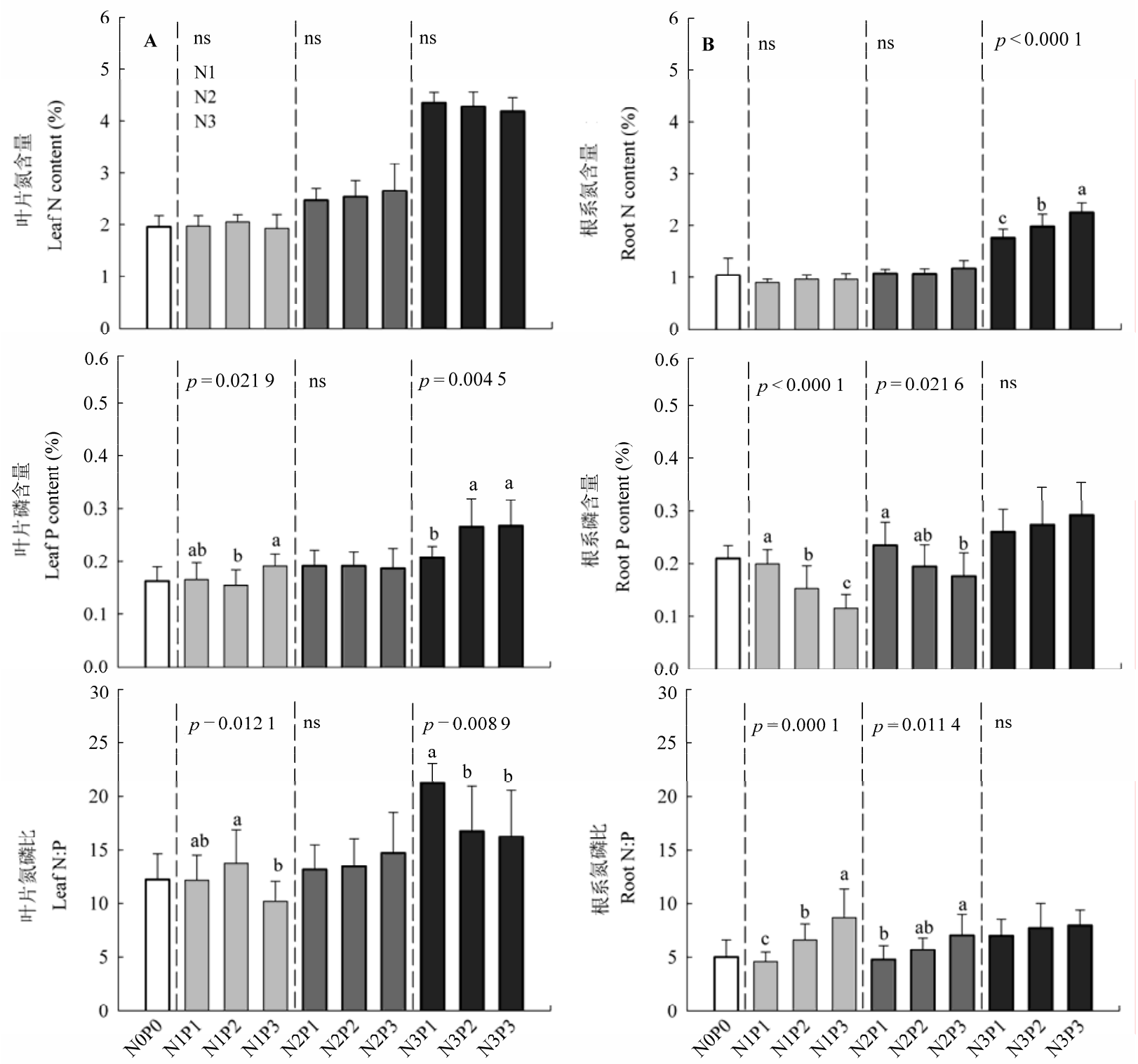

处 理 Treatment

处 理 Treatment

图3 氮、磷添加对羊草叶片 $(A)$ 和根系 $(B) \mathrm{N} 、 \mathrm{P}$ 含量及 $\mathrm{N}: \mathrm{P}$ 比的影响(平均值土标准误差)。不同小写字母代表在相同 $\mathrm{N}$ 添加水 平下, 不同 $\mathrm{P}$ 添加处理间差异显著 $(p<0.05), P$ 值为显著性水平, ns表示P处理间差异不显著。N0P0, 对照; N1、N2、N3分别表 示低、中、高N水平; P1、P2、P3分别表示低、中、高P水平。

Fig. 3 Effects of $\mathrm{N}$ and P additions on leaf (A) and root (B) N, P, and N:P ratios of Leymus chinensis (mean $\pm S E$ ). Different letters indicate significant difference $(p<0.05)$ among different $\mathrm{P}$ treatments at the same $\mathrm{N}$ level. $P$ values indicate significant levels, and ns indicates non-significant difference among P treatments. N0P0, control; N1, N2, N3 represent low, moderate and high N levels, and P1, P2, P3 represent low, moderate and high P levels.

在低、中N水平对 $P$ 添加的响应不明显, 而在高 $\mathrm{N}$ 水 平有降低的趋势(图4)。SRL对 N和P添加的响应明显 强于 $S L A$, 在低N水平, SRL随着P添加梯度而增加, 但在高N水平, 则有降低的趋势。

\section{5 地上性状与地下性状之间的关系}

对所有处理下羊草的地上与地下性状的相关分 析表明, 羊草的地上生物量与地下生物量之间没有
显著的相关性, 而 $S L A$ 与 $S R L\left(R^{2}=0.04, p=0.0558\right)$ 、 叶片 $\mathrm{N}$ 与根系 $\mathrm{N}$ 含量 $\left(R^{2}=0.82, p<0.0001\right)$ 、叶片 $\mathrm{P}$ 与根系 $\mathrm{P}$ 含量 $\left(R^{2}=0.28, p<0.0001\right)$ 之间均呈显著 的正相关关系(图5)。

\section{6 低 $\mathrm{N}$ 和高 $\mathrm{N}$ 水平下植物功能性状之间的关系}

整株性状与叶片、根系性状的相关分析表明, 在低 $\mathrm{N}$ 水平的所有 $\mathrm{P}$ 添加处理中, 羊草的地上生物 


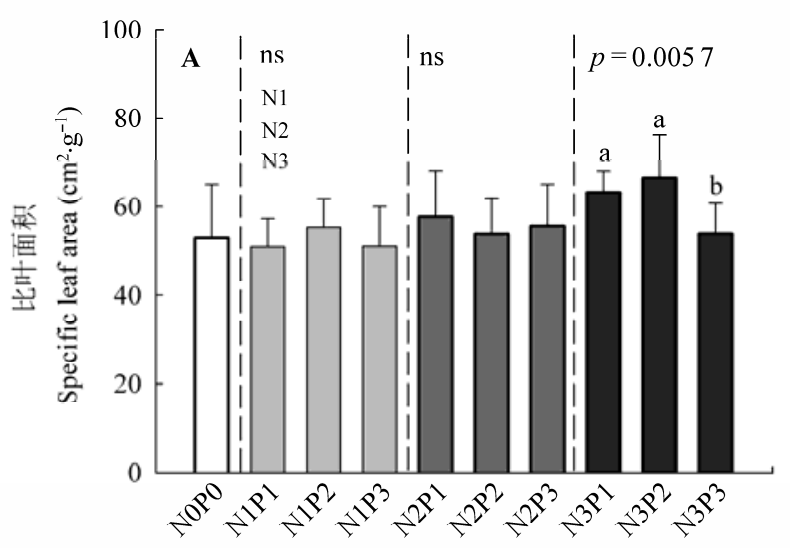

处理 Treatment

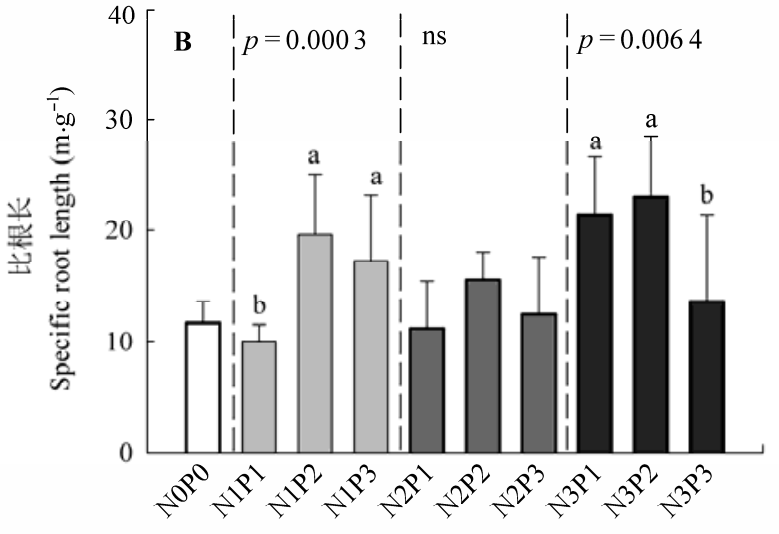

处理 Treatment

图4 氮、磷添加对羊草的比叶面积(A)和比根长 (B)影响(平均值土标准误差)。不同字母代表在相同 $\mathrm{N}$ 添加水平下, 不同 $\mathrm{P}$ 添加 处理之间差异显著 $(p<0.05), p$ 值为显著性水平, ns表示 $\mathrm{P}$ 处理间差异不显著。 NOP0, 对照; N1, N2, N3分别表示低、中、高N水 平; P1, P2, P3分别表示低、中、高P水平。

Fig. 4 Effects of $\mathrm{N}$ and $\mathrm{P}$ additions on specific leaf area (A) and specific root length (B) of Leymus chinensis (mean $\pm S E$ ). Different letters indicate significant difference $(p<0.05)$ among different $\mathrm{P}$ treatments at the same $\mathrm{N}$ level. $p$ values indicate significant levels, and ns indicates non-significant difference among P treatments. NOP0, control; N1, N2, N3 represent low, moderate and high N levels, and P1, P2, P3 represent low, moderate and high P levels.

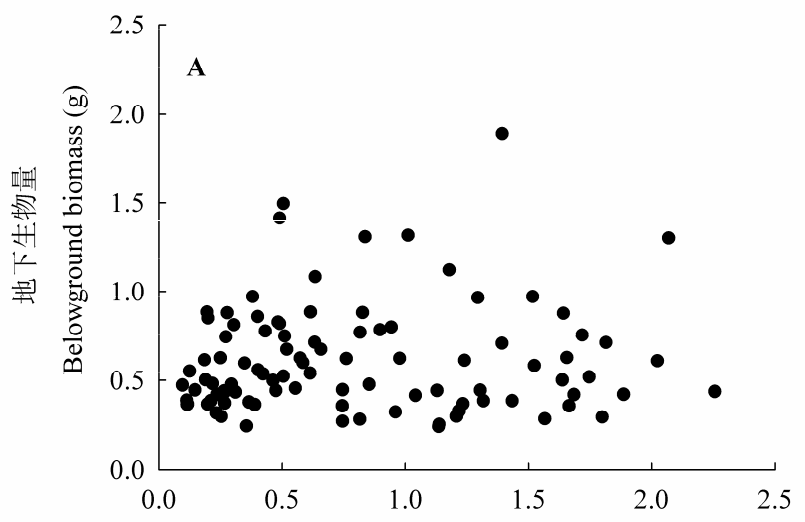

地上生物量 Aboveground biomass (g)

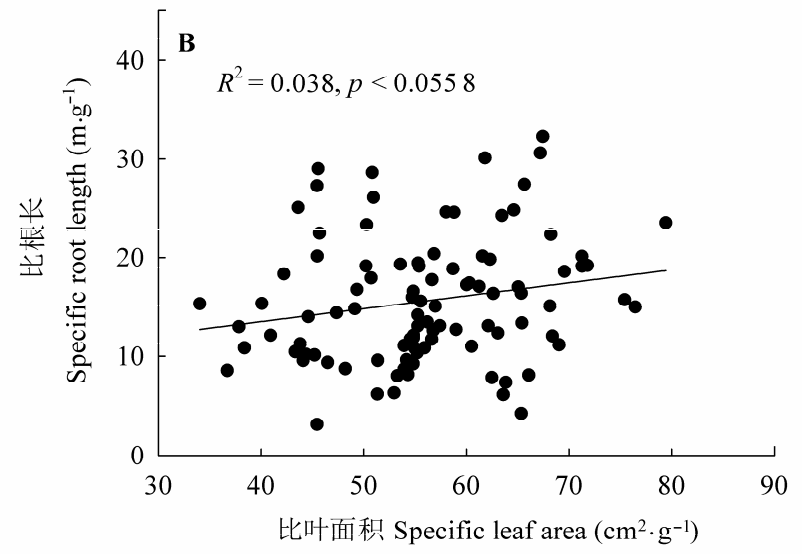

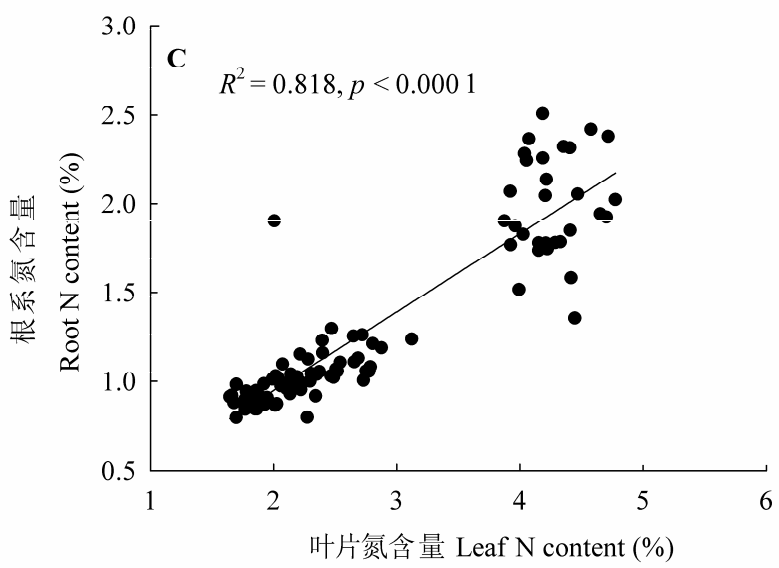

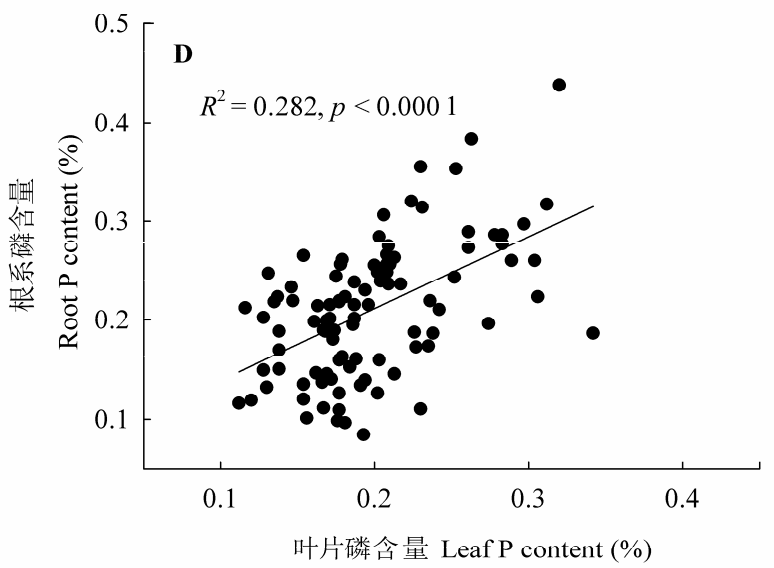

图5 羊草个体地上与地下生物量(A)、比叶面积与比根长 $(\mathbf{B}) 、$ 叶片与根系 $N 、 P$ 含量 $(\mathbf{C} 、 \mathbf{D})$ 之间的关系。

Fig. 5 Relationships between individual aboveground and belowground biomass (A), specific leaf area and specific root length (B), leaf $\mathrm{N}$ and root $\mathrm{N}$ contents (C), leaf $\mathrm{P}$ and root $\mathrm{P}$ contents (D) of Leymus chinensis. 
量与 $P_{\mathrm{n}}$ 和 $S R L$ 正相关, 而地下生物量、根冠比均与根 系 $\mathrm{P}$ 含量正相关(表2)。此外, 叶片与根系性状之间的 相关分析表明 $S L A$ 与叶片 $\mathrm{N}(r=0.67)$ 和根系 $\mathrm{N}$ 含量 $(r$ $=0.57)$ 正相关, $S R L$ 与根系 $\mathrm{N}$ 含量 $(r=0.37)$ 正相关, 而与根系 $\mathrm{P}$ 含量 $(r=-0.37)$ 负相关, $P_{\mathrm{n}}$ 与根系 $\mathrm{N}$ 含量 正相关 $(r=0.49)$ 。

在高 $\mathrm{N}$ 水平的所有 $\mathrm{P}$ 添加处理中, 羊草的地上 生物量、总生物量均与 $S L A$ 和SRL正相关, 而与 $W U E$ 负相关, 总生物量还与 $P_{\mathrm{n}}$ 负相关; 羊草的地下生物 量、根冠比均与根系 $\mathrm{N}$ 含量负相关(表2)。叶片和根 系性状之间的相关分析表明, SLA 与 $P_{\mathrm{n}}(r=-0.34)$ 和 根系 $\mathrm{P}$ 含量 $(r=-0.38)$ 负相关, 而 $P_{\mathrm{n}}$ 与根系 $\mathrm{N}(r=$ $0.54)$ 含量正相关。

\section{3 讨论}

以往关于羊草对养分添加的实验研究多是在野 外的自然生境中进行的(Chen et al., 2005; 万宏伟 等, 2008; Lan \& Bai, 2012; Lü et al., 2013; 白雪等, 2014), 或是通过盆栽实验, 但只针对某一方面的生 理生态特性进行研究(王云龙等, 2004; Xu \& Zhou, 2006)。相比以往研究, 本研究通过盆栽实验, 利用 温室控制稳定的温度和湿度, 添加定量的有效态 $\mathrm{N}$ 和 $\mathrm{P}$, 排除了气候变化、环境异质性和群落内物种竞 争等干扰因素。本实验设计了低、中、高 3 个 $\mathrm{N}$ 和 $\mathrm{P}$ 梯度及其交互作用, 以更好地模拟养分供应的不同 比例, 较为系统地测定了羊草的地上、地下关键功 能性状, 以期更好地揭示羊草对不同养分环境的响 应及适应机制。

\subsection{N、P添加对羊草生物量分配和养分分配的影 响及机制}

我们的结果表明, 羊草的地上生物量主要受 $\mathrm{N}$ 添加的影响, 高 $\mathrm{N}$ 水平下, 羊草的地上生物量约为 低 $\mathrm{N}$ 水平的3.5倍, 仅在低 $\mathrm{N}$ 水平下, $\mathrm{P}$ 添加会提高羊 草的地上生物量, 说明在 $\mathrm{N}$ 供应水平较低的情况下, $\mathrm{P}$ 添加对羊草生长有一定的促进作用。羊草的总生 物量也主要受 $\mathrm{N}$ 添加的影响, 中 $\mathrm{N}$ 和高 $\mathrm{N}$ 水平羊草的 总生物量约为低 $\mathrm{N}$ 水平的2.0-3.0倍。这些结果表明, 羊草的个体生长主要受 $\mathrm{N}$ 素限制, 这与基于野外养 分添加实验的研究结果较为一致, 例如: 白雪等 (2014)研究发现 N添加对羊草生长具有明显的促进 效应, 使其个体生物量显著增加; 潘庆民等(2005) 研究表明 $\mathrm{N}$ 添加显著提高了羊草群落的地上生物
量。与地上生物量相反, 羊草的地下生物量主要受 $\mathrm{P}$ 添加的影响, 尤其在中 $\mathrm{N}$ 和高 $\mathrm{N}$ 水平, $\mathrm{P}$ 添加会显著 降低羊草的地下生物量。羊草的根冠比受 $N 、 P$ 添加 的共同影响, 随着 $\mathrm{N}$ 和 $\mathrm{P}$ 添加的梯度, 根冠比显著降 低, 表明 $\mathrm{N} 、 \mathrm{P}$ 添加均促进了植物向地上生物量的分 配。此结果与黄菊荤等(2012)通过盆栽实验研究羊 草对 N、P添加的响应结果较为一致。通过分析 $N$ 、 $\mathrm{P}$ 在叶片与根系生物量之间的分配, 我们的研究发 现N、P添加均显著促进了羊草向叶片生物量的 $\mathrm{N}$ 、 $\mathrm{P}$ 分配, 在高 $\mathrm{N}$ 水平, $\mathrm{N} 、 \mathrm{P}$ 向叶片生物量的分配比例 比低 $N$ 水平分别高出 4.2 倍和 2.8 倍。而且, 羊草的叶 片 $\mathrm{N}$ 含量显著高于根系 $\mathrm{N}$ 含量, $\mathrm{N} 、 \mathrm{P}$ 添加提高了叶片 $\mathrm{P}$ 含量, 但降低了根系 $\mathrm{P}$ 含量, 也表明 $\mathrm{N} 、 \mathrm{P}$ 添加促进 了羊草向叶片生物量的N、P分配。Müller等(2000) 也认为在养分条件较好时, 植物倾向于将生物量较 多地分配于地上部分, 在养分条件较差时则倾向于 分配至地下部分。

羊草 $N 、 P$ 向叶片的分配比例增加, 主要是因为 随着 $\mathrm{N} 、 \mathrm{P}$ 添加, 羊草由对地下养分的竞争逐渐转化 为对地上光资源的竞争(Pan et al., 2011; Lan \& Bai, 2012)。这不仅是羊草对养分环境波动的适应, 也有 利于其在自然群落中的竞争。因为随着 $\mathrm{N}$ 和 $\mathrm{P}$ 添加, 根系的养分吸收能力逐渐过剩, 将更多的资源分配 给地上部分, 植株变得高大, 以利于获得更多的光 照(Lan \& Bai, 2012)。SLA和SRL反映了植物对光强 和土壤养分的获取能力(Cornelissen et al., 2003)。本 研究中, 羊草 $S R L$ 在中 $\mathrm{N}$ 水平最低, 而在低 $\mathrm{N}$ 和高 $\mathrm{N}$ 水平较高。其原因可能是, 在中 $\mathrm{N}$ 水平, 羊草对养分 资源的吸收高于低 $N$ 水平, 因此羊草降低 $S R L$ 以适 应较高浓度的养分环境。随着 $\mathrm{N}$ 添加, 高 $\mathrm{N}$ 水平促进 了植株的养分周转(Marklein \& Houlton, 2012), 细 根比例增加以满足植物快速生长的养分需求, 因此 羊草 $S R L 又$ 随之增加。本研究中, 羊草的 $S L A$ 较为稳 定, 在低 $\mathrm{N} 、 \mathrm{P}$ 水平, 植物分配较多的资源于叶片以 提高其最大光合潜能, 而随着 $\mathrm{N} 、 \mathrm{P}$ 添加, 羊草生长 不受养分限制, 其增加 $\mathrm{N} 、 \mathrm{P}$ 分配也不能提高光合速 率, 因而SLA较为稳定。万宏伟等(2008)认为, 随着 $\mathrm{N}$ 添加导致光资源竞争加剧, 不同物种对光资源的 竞争策略和竞争力有显著差异, 而羊草能够通过提 高SLA和叶片 $\mathrm{N}$ 含量提高其对光资源的利用。

我们的研究表明, 相对于地上性状, P添加对羊 草的地下性状影响更大, 其原因可能是, 羊草是根 
系与从枝菌根真菌(AMF)共生的物种, 而菌根真菌 更有利于根系对P的吸收(Li \& Feng, 2001)。已有研 究表明, 不同植物的共生菌根效应存在很大差异, 可以是正效应、中性或负效应，与植物生长的养分 环境有关。在土壤有效养分供应充足的情况下, 菌 根共生对植物生长没有积极影响, 甚至会导致植物 生物量下降(Hart et al., 2003; 雷圭等, 2013)。本研究 中, 在中、高 $\mathrm{N}$ 水平, $\mathrm{P}$ 添加显著降低了羊草的根系 $\mathrm{P}$ 含量和地下生物量, 其原因可能是在 $\mathrm{N}$ 供应较高 条件下, 菌根真菌对 $\mathrm{P}$ 吸收的作用有限, 而 $\mathrm{P}$ 的过量 添加抑制了根系生长。植物功能性状之间的权衡 (tradeoffs)或协同(synergies)关系, 反映了植物为适 应环境变化所采取的策略 (Lavorel \& Grigulis, 2012)。本研究中, 尽管羊草的地上生物量与地下生 物量之间没有显著的相关性, 但从总的趋势看, 沿 着 $\mathrm{N} 、 \mathrm{P}$ 添加梯度, 羊草的地上生物量增加, 而地下 生物量降低, 根冠比也呈降低趋势, 表明羊草在地 上与地下部分的资源分配方面采取了一定的权衡策 略。羊草的叶片 $\mathrm{N}$ 与根系 $\mathrm{N}$ 含量、叶片 $\mathrm{P}$ 与根系 $\mathrm{P}$ 含 量之间均呈显著的正相关关系, 其原因主要是根系 从土壤中吸收 $\mathrm{N} 、 \mathrm{P}$ 进而传输到叶片, 因而叶片与根 系养分表现出高度的协同性。羊草的 $S L A$ 与 $S R L$ 之间 呈较弱的正相关关系, 表明羊草叶片与根系在资源 获取和利用方面具有相对的独立性。

\section{2 低 $\mathrm{N}$ 和高 $\mathrm{N}$ 水平下羊草对 $\mathrm{P}$ 添加的适应机制}

在低 $\mathrm{N}$ 水平, 随着 $\mathrm{P}$ 添加梯度, 羊草的地上生物 量、叶片 $\mathrm{P}$ 含量和 $S R L$ 增加, 而地下生物量、叶片和 根系 $\mathrm{N}$ 含量和 $S L A$ 变化不大。表明在低N水平, $\mathrm{P}$ 添加 促进了地上部分生长, 而对地下部分影响不大。羊 草的地上生物量与 $P_{\mathrm{n}}$ 和 $S R L$ 呈正相关关系, 而地下 生物量与根系 $\mathrm{P}$ 含量呈正相关关系, $S R L$ 与根系 $\mathrm{N}$ 含 量呈正相关关系。这些结果表明, 羊草主要通过提 高光合能力和根系对 $\mathrm{N}$ 的获取能力促进地上部分的 生长, 而根系对 $\mathrm{P}$ 的吸收有利于地下部分的生长。

在高 $\mathrm{N}$ 水平, 随着 $\mathrm{P}$ 添加梯度, 羊草的地上生物 量和叶片 $\mathrm{N}$ 含量无明显变化, 而地下生物量降低, 叶片 $\mathrm{P}$ 含量和根系 $\mathrm{N}$ 含量增加。羊草的地上生物量、 总生物量均与 $S L A$ 和 $S R L$ 呈正相关关系, 而与 $W U E$ 呈负相关关系, 总生物量还与 $P_{\mathrm{n}}$ 呈负相关关系, 羊 草的地下生物量与根系 $\mathrm{N}$ 含量呈负相关关系。这些 结果表明在高 $\mathrm{N}$ 水平, $\mathrm{P}$ 添加对羊草的个体生长无明 显促进作用, 甚至地下部分明显受到 $\mathrm{P}$ 素抑制, 羊
草主要通过保持较高的 $S L A$ 和 $S R L$ 提高对光资源的 截获能力和根系对 $\mathrm{N}$ 的获取和吸收能力维持地上部 分的生长。

羊草在对养分添加做出响应的同时, 虽然其生 物量和生理性状有显著响应, 但也具有保持生物计 量化学稳定的特性, 即相对于变化的外界养分供应 而言, 植物在一定范围内具有保持自身 $\mathrm{N}: \mathrm{P}$ 稳定的 能力(Elser et al., 2000; Zhang et al., 2003)。本实验结 果也表明, 尽管羊草组织(叶片和根系)的 $\mathrm{N}$ 或 $\mathrm{P}$ 含量 对养分添加有着较明显的响应, 但羊草的叶片 N:P 始终保持在12-15之间, 而在较高的 $\mathrm{N}$ 和P添加水平, 羊草的 $\mathrm{N}: \mathrm{P}$ 基本维持在14-15左右，与传统的养分限 制理论中以 $N: P$ 为 14 或 16 作为区分 $N$ 或 $P$ 限制的阈值 较为相符(Koerselman \& Meuleman, 1996)。我们的 研究还发现在盆栽实验中, N和P的作用在一定程度 上是互补的。一般认为叶片 $\mathrm{N}$ 含量是直接与植物光 合能力相关的指标, 本实验中高 $\mathrm{N}$ 处理下羊草叶片 的 $\mathrm{N}$ 含量显著高于其他处理, 但从光合速率的数据 看, 高 $\mathrm{N}$ 下叶片光合速率并没有随之升高, 而是随 着 $\mathrm{P}$ 添加的增加而显著上升, 说明在本实验中, $\mathrm{P}$ 可 能是羊草光合作用的重要限制因子。早期的一些研 究发现部分植物的光合作用是受到P限制的(Terry \& Ulrich, 1973; Lapointe, 1987), 而Reich等(2009)通 过对多个生态系统的整合分析, 发现整体来看叶片 $\mathrm{N}$ 和 $\mathrm{P}$ 含量均与其最大光合速率显著相关 $(p<$ $0.0001)$, 但全因子的回归模型显示 $\mathrm{N}$ 是主因子 $(p<$ $\left.0.0001, R^{2}=0.52\right)$, 而 $\mathrm{N}$ 和P有着显著的交互 作用。

\section{4 结论}

我们的研究表明: 羊草个体的地上生物量和总 生物量主要受 $\mathrm{N}$ 添加的影响, 而地下生物量主要受 $\mathrm{P}$ 添加的影响, 尤其在中 $\mathrm{N}$ 和高 $\mathrm{N}$ 水平, $\mathrm{P}$ 添加显著降 低了羊草的地下生物量。N、P添加降低了羊草的根 冠比, 促进了羊草生物量向地上部分的分配和 $N 、 P$ 向叶片的分配。相对于地上性状, P添加对羊草的地 下性状影响更大, 在低 $\mathrm{N}$ 和高 $\mathrm{N}$ 条件下, 羊草对 $\mathrm{P}$ 添 加的适应机制不同。羊草的SLA与SRL之间呈较弱的 正相关关系, 表明叶片与根系在资源获取和利用方 面具有相对的独立性。我们的研究结果对退化草地 生态系统的恢复与管理具有重要的指导意义。采用 养分添加措施时, 应考虑草地生态系统自身的养分 状况, 设置适当的 N、P肥施用比例。对于养分贫㾑 
的草地，施用 $\mathrm{N}$ 肥是提高草地生产力的首选措施; 对于 $N$ 素不匮乏的草地, 适当添加 $P$ 肥也有助于生 产力的提高; 但过量添加N、P肥，对于生产力的提 高效应不大, 尤其是过量添加P肥甚至会抑制地下 部分的生长, 造成肥料浪费和环境污染。另外, N、 $\mathrm{P}$ 添加能够提高草地生产力, 但同时也改变了地上地下生物量分配, 可能引起光资源或水分的相对限 制, 因此利用养分添加管理手段还需要综合考虑生 态系统功能的平衡。

基金项目 国家科技支撑计划(2012BAD16B03)和 中国科学院战略性先导科技专项(XDA05050400)。

致谢 中国科学院植物研究所兰志春、邢稳和李建 军博士生在本实验中给予了大力帮助, 在此表示感 谢。

\section{参考文献}

Bai X, Cheng JH, Zheng SX, Zhan SX, Bai YF (2014). Ecophysiological responses of Leymus chinensis to nitrogen and phosphorus additions in a typical steppe. Chinese Journal of Plant Ecology, 38, 103-115. (in Chinese with English abstract) [白雪, 程军回, 郑淑霞, 詹书侠, 白永 飞 (2014). 典型草原建群种羊草对氮磷添加的生理生 态响应. 植物生态学报, 38, 103-115.]

Bai YF, Wu JG, Clark CM, Naeem S, Pan QM, Huang JH, Zhang LX, Han XG (2010). Tradeoffs and thresholds in the effects of nitrogen addition on biodiversity and ecosystem functioning: Evidence from Inner Mongolia grasslands. Global Change Biology, 16, 358-372.

Chen SP, Bai YF, Zhang LX, Han XG (2005). Comparing physiological responses of two dominant grass species to nitrogen addition in Xilin River Basin of China. Environmental and Experimental Botany, 53, 65-75.

Cornelissen JHC, Lavorel S, Garnier E, Díaz S, Buchmann N, Gurvich DE, Reich PB, ter Steege H, Morgan HD, van der Heijden MGA, Pausas JG, Poorter H (2003). A handbook of protocols for standardised and easy measurement of plant functional traits worldwide. Australian Journal of Botany, 51, 335-380.

Elser JJ, Fagan WF, Denno RF, Dobberfuhl DR, Folarin A, Huberty A, Interlandi S, Kilham SS, McCauley E, Schulz KL, Siemann EH, Sterner RW (2000). Nutritional constraints in terrestrial and freshwater food webs. Nature, 408, 578-580.

Hart MM, Reader RJ, Klironomos JN (2003). Plant coexistence mediated by arbuscular mycorrhizal fungi. Trends in Ecology \& Evolution, 18, 418-423.

Huang JY, Xu P, Yu HL, Yuan ZY, Li LH (2012). Responses of biomass, nutrient allocation of Leymus chinensis along N, P and water gradients. Pratacultural Science, 29,
1589-1595. (in Chinese with English abstract) [黄菊荣, 徐鹏, 余海龙, 袁志友, 李凌浩 (2012). 羊草生物量和 养分分配对养分和水分添加的响应. 草业科学, 29, 1589-1595.]

Koerselman W, Meuleman AFM (1996). The vegetation N:P ratio: A new tool to detect the nature of nutrient limitation. Journal of Applied Ecology, 33, 1441-1450.

Lan ZC, Bai YF (2012). Testing mechanisms of N-enrichmentinduced species loss in a semiarid Inner Mongolia grassland: Critical thresholds and implications for long-term ecosystem responses. Philosophical Transactions of the Royal Society B: Biological Sciences, 367, 3125-3134.

Lapointe BE (1987). Phosphorus-and nitrogen-limited photosynthesis and growth of Gracilaria tikvahiae (Rhodophyceae) in the Florida Keys: An experimental field study. Marine Biology, 93, 561-568.

Lavorel S, Grigulis K (2012). How fundamental plant functional trait relationships scale-up to trade-offs and synergies in ecosystem services. Journal of Ecology, 100, 128-140.

Lei Y, Hao ZP, Chen BD (2013). Effects of indigenous AM fungi and neighboring plants on the growth and phosphorus nutrition of Leymus chinensis. Acta Ecologica Sinica, 33, 1071-1079. (in Chinese with English abstract) [雷圭, 郝志鹏, 陈保冬 (2013). 土著菌根真菌和混生植物对羊 草生长和磷营养的影响. 生态学报, 33, 1071-1079.]

Li XL, Feng G (2001). Eco-Physiology of Arbuscular Mycorrhiza. Sino-Culture Press, Beijing. 178-199.

Li YH (1993). Grazing dynamics of the species diversity in Aneurolepidium chinense steppe and Stipa grandis steppe. Acta Botanica Sinica, 35, 877-884. (in Chinese with English abstract) [李永宏 (1993). 放牧影响下羊草草原和大 针茅草原植物多样性的变化. 植物学报, 35, 877-884.]

Liu GF, Freschet GT, Pan X, Cornelissen JHC, Li Y, Dong M (2010). Coordinated variation in leaf and root traits across multiple spatial scales in Chinese semi-arid and arid ecosystems. New Phytologist, 188, 543-553.

Lü XT, Reed S, Yu Q, He NP, Wang ZW, Han XG (2013). Convergent responses of nitrogen and phosphorus resorption to nitrogen inputs in a semiarid grassland. Global Change Biology, 19, 2775-2784.

Marklein AR, Houlton BZ (2012). Nitrogen inputs accelerate phosphorus cycling rates across a wide variety of terrestrial ecosystems. New Phytologist, 193, 696-704.

Müller I, Schmid B, Weiner J (2000). The effect of nutrient availability on biomass allocation patterns in 27 species of herbaceous plants. Perspectives in Plant Ecology, Evolution and Systematics, 3, 115-127.

Pan QM, Bai YF, Han XG, Yang JC (2005). Effects of nitrogen additions on a Leymus chinensis population in typical steppe of Inner Mongolia. Acta Phytoecologica Sinica, 29, 311-317. (in Chinese with English abstract) [潘庆民, 白

www.plant-ecology.com 
永飞, 韩兴国, 杨景成 (2005). 氮素对内蒙古典型草原 羊草种群的影响. 植物生态学报, 29, 311-317.]

Pan QM, Bai YF, Wu JG, Han XG (2011). Hierarchical plant responses and diversity loss after nitrogen addition: Testing three functionally-based hypotheses in the Inner Mongolia grassland. PLoS ONE, 6, e20078. doi: 10.1371/journal.pone.0020078.

Reich PB, Oleksyn J, Wright IJ (2009). Leaf phosphorus influences the photosynthesis-nitrogen relation: A cross-biome analysis of 314 species. Oecologia, 160, 207-212.

Terry N, Ulrich A (1973). Effects of phosphorus deficiency on the photosynthesis and respiration of leaves of sugar beet. Plant Physiology, 51, 43-47.

Wan HW, Yang Y, Bai SQ, Xu YH, Bai YF (2008). Variations in leaf functional traits of six species along a nitrogen addition gradient in Leymus chinensis steppe in Inner Mongolia. Journal of Plant Ecology (Chinese Version), 32, 611-621. (in Chinese with English abstract) [万宏伟, 杨 阳, 白世勤, 徐云虎, 白永飞 (2008). 羊草草原群落6种 植物叶片功能特性对氮素添加的响应. 植物生态学报, 32, 611-621.]

Wang RZ (1997). The niche breaths and niche overlaps of main plant populations in Leymus chinensis grassland for grazing. Acta Phytoecologica Sinica, 21, 304-311. (in Chinese with English abstract) [王仁忠 (1997). 放牧影响下羊草 草地主要植物种群生态位宽度与生态位重叠的研究. 植物生态学报, 21, 304-311.]

Wang YH, He XY, Zhou GS (2002). Study on the responses of Leymus chinensis steppe to grazing in Songnen Plain. Acta
Agrestia Sinica, 10, 45-49. (in Chinese with English abstract) [王玉辉, 何兴元, 周广胜 (2002). 放牧强度对羊 草草原的影响. 草地学报, 10, 45-49.]

Wang YL, Xu ZZ, Zhou GS (2004). Changes in biomass allocation and gas exchange characteristics of Leymus chinensis in response to soil water stress. Acta Phytoecologica Sinica, 28, 803-809. (in Chinese with English abstract) [王 云龙, 许振柱, 周广胜 (2004). 水分胁迫对羊草光合产 物分配及其气体交换特征的影响. 植物生态学报, 28 , 803-809.]

Xu JC, Xu XY (2013). A study on growth rate and the growth rate hypothesis in Leymus chinensis. Pratacultural Science, 30, 74-79. (in Chinese with English abstract) [徐劲 草, 许新宜 (2013). 羊草生长率的研究和生长率假说的 验证. 草业科学, 30, 74-79.]

Xu ZZ, Zhou GS (2006). Combined effects of water stress and high temperature on photosynthesis, nitrogen metabolism and lipid peroxidation of a perennial grass Leymus chinensis. Planta, 224, 1080-1090.

Zhang LX, Bai YF, Han XG (2003). Application of N:P stoichiometry to ecology studies. Acta Botanica Sinica, 45, 1009-1018.

Zhang LX, Bai YF, Han XG (2004). Differential responses of $\mathrm{N}: \mathrm{P}$ stoichiometry of Leymus chinensis and Carex korshinskyi to $\mathrm{N}$ additions in a steppe ecosystem in Nei Mongol. Acta Botanica Sinica, 46, 259-270.

责任编委: 吕晓涛 责任编辑: 王 葳

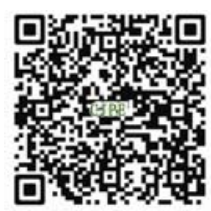

植物生态学报官网

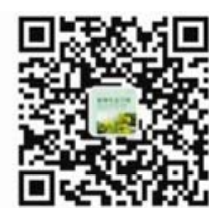

微信订阅号

期刊及学科

相关信息发布

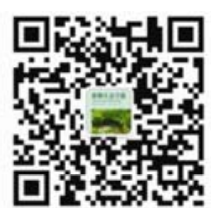

微信服务号

稿件状态查询

全文检索汶览 